\title{
The use of Selective Serotonin Re-uptake Inhibitors (SSRIs) in the treatment of depressive disorders in children and adolescents
}

\author{
ANTHONY JAMES
}

\section{INTRODUCTION}

There is a controversy about the use of SSRIs in the treatment of depressive disorders in children and adolescents. Media concern that SSRIs might precipitate suicidal acts in teenagers was highlighted in a BBC Panorama programme (BBC News, 2003). Shortly afterwards, the pharmaceutical companies GlaxoSmithKline and Wyeth issued warnings about their products Paroxetine and Venlafaxine. In December 2003, the Committee on Safety of Medicines (CSM) reviewed the evidence of published and unpublished trials of SSRIs for the treatment of depression in children and adolescents and other antidepressants - Venlafaxine, and Mirtazapine (Committee on Safety of Medicines, 2003). The CSM raised two areas of concern: (1) efficacy - apart from fluoxetine SSRIs appeared to be no more effective than placebo; and (2) safety -an apparent increase in self-harm and suicidal thoughts in those treated with SSRIs. On this basis the CSM no longer recommended the use of SSRIs in the treatment of depressed children with the exception of Fluoxetine, and then only under specialist supervision. In the United Kingdom the use of all the SSRIs including Fluoxetine is off licence for the treatment of depression in this age group. In Sept 2004 the US Food and Drug Administration (FDA) issued warnings about the increased risk of suicidal thoughts and actions with all

Address for correspondence: Dr. A. James, Consultant Adolescent Psychiatrist at the Highfield Family and Adolescent Unit Oxford, and Honorary Senior Lecturer, University of Oxford, Oxford OX3 7JX (United Kingdom).

E-mail: anthony.james@psychiatry.oxford.ac.uk

Declaration of Interest: Dr A James has no affiliation with any drug company. He has received sponsorship for educational travel from Janssen Cilag, AstraZenca and Eli- Lilly.
SSRIs, but recommended that they were not to be contraindicated (US Food and Drugs Administration, 2004). The National Institute for Clinical Excellence (NICE) in the UK has commissioned a clinical guideline, based upon published evidence only, for the management of depressive disorders in children and adolescents.

\section{SSRIS USAGE}

Since the introduction of the SSRIs in the early 1990's, there has been a dramatic increase in their prescription in juveniles (Gunnell \& Ashby, 2004). Currently, it is estimated that are 40,000 depressed adolescents in the UK are taking SSRIs (Ramchandai, 2004a). This increased usage reflects a combination of factors: (1) a rise in referrals generally to child and adolescent mental health services, of which a high proportion are recognised and diagnosed as suffering from depression; (2) evidence from published trials available at the time, and first hand clinical experience, suggesting that SSRIs were effective; (3) the reduced toxicity of SSRIs in comparison to the older tricyclic antidepressants. This was regarded as a particularly important factor in the treatment of adolescents, where overdosing reaches a peak, especially amongst females (Hawton et al., 2003).

\section{THE ADVICE OF THE COMMITTEE ON SAFETY OF MEDICINES}

The advice of the Committee on Safety of Medicines was based on published data and unpublished reports from the Pharmaceutical Companies. A total of 13 trials were evaluated (Fluoxetine $x$ 2, Sertraline $x$ 2, Citalopram $\times 2$, Paroxetine $\times 3$, Venlafaxine $\times 2$, 
Mirtazapine x 2) There were no trials of Fluvoxamine or Escitalopram and the review was restricted to the treatment of depressive disorders in children and adolescents, and did not focus upon the use of SSRIs for the treatment of obsessive compulsive disorder (OCD), anxiety states or post-traumatic stress disorder (PTSD). The CSM recommended that Citalopram, Paroxetine, Venlafaxine, Sertraline, Mirtazapine, Escitalopram and Fluvoxamine should not be prescribed as a new therapy for major depressive disorder in under 18 's, as the benefits did not seem to outweigh risks, but an established treatment could be continued. Fluoxetine could be used, but only under specialist advice. The Committee of the Safety of Medicines (2004) further clarified that a subgroup analysis of the two age groups 7-12 and 13-17 did show any statistically significant effect, although the effect size often appeared greater in adolescents. Judgements could not be made regarding the risks/benefits balance associated with different severities of depression.

Following the CSM's injunction, there has been considerable criticism of the pharmaceutical industry for not publishing negative or unfavourable drug trials (Ramchandani 2004a, b; Garland, 2004; Whittington et al., 2004; Jureidini et al., 2004;Wessely et al., 2004). A number of other criticisms of the research, which formed the basis of the CSM advice, have been made (Whittington et al., 2004; Jureidini et al., 2004) including: (1) almost all trials were industry funded, and in some cases this was not disclosed; (2) reporting of statistical significance which was of doubtful clinical importance (Wagner et al., 2003); (3) poor quality of reporting by overstating results. For example, Keller et al. (2001), Emslie et al. (1997) did not highlight the failure of the studies to show any significant improvement over placebo on their primary outcome measures, but instead, reported positive secondary outcome measures;(4) incorrect use of categorical measures - categorical measures are likely to inflate small differences between groups. Three of six trials used categorical outcomes based upon continuous measures; (5) blinding of subjects doubtful; (6) high withdrawal rates form trials ranging between 17 and $34 \%$; intention to treat analyses (ITT) were done but no analyses were undertaken at the end of treatment; (7) definition of suicidality was unclear and varied between trials and, indeed, suicidality was often not reported; (8) where trials have been published they seemed to have been based upon samples that are not typical of the cases seen in the UK or European clinical practice i.e. children, or those without comorbidity or suicidal ideation.

\section{Efficacy}

In a review (Jureidini et al., 2004) of six placebo-controlled trials (Keller et al., 2001; Simeon et al., 1990; Mandoki et al., 1997; Emslie et al., 1997; 2002; Wagner et al., 2003) involving 477 patients and 464 controls, only 14 out of 42 reported measures showed a statistical advantage for antidepressants. None of the patient or parent report measures showed advantage for antidepressants. Further, 4 out of 6 trials did not show any significant advantage for drug over placebo on primary outcome measures. A meta-analysis using standardised mean difference (Hedges method) with a random effects model involving all continuous measures of depression and health related quality of life, showed only a modest effect size of 0.26 (95\% confidence interval 0.13-0.14). This small effect size was estimated to equate to only a modest 3-4\% change on the Childhood Depression Rating Scale (CDRS-R) (Poznanski et al., 1979;1996).

A another meta-analysis by Whittington et al. (2004) of randomised controlled trials (RCT's) of SSRIs versus placebo, including those in the CSM review, found a favourable risk-benefit profile for published data, in particular fluoxetine, however, addition of the unpublished led to an unfavourable risk/benefit profile. A major difficulty, however, in investigating and interpreting the efficacy of antidepressants in children and adolescents is the high placebo response, in some studies 50 and $60 \%$, which is considerably higher than that seen in adulthood.

Since the CSM warning, there has been a further study of citalopram (Wagner et al., 2004) involving 89 children and adolescents and 85 controls. A significant difference in drug versus placebo was found at week 1 , reaching a maximum at week 6 . Again, the clinical significance of a 5 -point difference on the CDRS-R is questionable.

\section{Suicidality}

There are problems with the reporting of suicidality in the studies reviewed by the CSM. In part, this may be due to the fact that there is no standard, or agreed definition of suicidality or deliberate self-harm (DSH). Importantly, most studies excluded patients at serious suicide risk, probably on ethical grounds.

To make sense of the CSM data on suicidality it is necessary to have a normal comparator. The year prevalence rate of deliberate self-harm amongst a community sample of UK adolescents is $6.9 \%$ ( $11.2 \%$ females; $3.2 \%$ males) and suicidal ideation $15 \%$ (22.4\% females; $8.5 \%$ males) (Hawton et al., 2002). Amongst depressed New Zealand adolescents the rate of deliberate self-harm is $13.8 \%$ 
(14.8\% girls; $11.2 \%$ boys) (Fergusson \& Woodward, 2002). It appears, therefore, that in all the trials the rates of DSH, suicidal ideation and suicide attempts are low.

The analysis by the CSM of the data on suicidality has been strongly criticised (Brent \& Birmaher, 2004) on the grounds that the suicidal rate in the drug treated group was not significantly higher than controls in any of the trials. Meta-analysis of the data from four trials (Gunnell \& Ashby, 2004) found a non significant increase in suicidality (using a pooled estimate, with a Bayesian random effects model, of 1.66 (95\% CI $0.83-3.5) \mathrm{p}=\mathrm{NS}$ ). The authors noted the variety of adverse outcomes: "suicidal attempts"; "suicidal ideation events"; "suicidal thoughts"; "self harm", possible "behaviors possibly related to suicidality". There were no suicides in the CSM database of 1,717 patients treated for an estimated period of risk of 170 years.

In a recent, well conducted multi-centre study, Treatment for Adolescents with Depression Study (TAPS) (Treatment for Adolescents with Depression Study Team, 2004), involving 439 12-17 year olds with moderate to severe depression, randomised to twelve weeks of fluoxetine (10-40mg), CBT, CBT plus fluoxetine or placebo group, the baseline rate of suicidal thinking was $29 \%$, which reduced in all groups. Fluoxetine in combination with $\mathrm{CBT}$ reduced suicidal ideation more than CBT or fluoxetine alone. Fluoxetine did not increase suicidal ideation in comparison to controls.

The suicide and undetermined death rates in young males, but not females, had shown a considerable rise between 1970 and 1998 (McClure, 2001). Recent worldwide epidemiological surveys, however (World Health Organization, 2003), have shown a reduction in suicide rates amongst 15-24 year olds of up to $33 \%$ in 15 countries. - $52 \%$ in Australia to $14 \%$ in Japan. Some have argued that this reduction coincided with the significant increase in the prescription of antidepressants in adolescents mostly SSRIs (Carlsten et al., 2001; Hawton et al., 2003; Isaacsson, 2000; Olfson et al., 2003). In Japan, where the suicide rate remained high until 1997, the late introduction of SSRIs coincided with a reduction in youth suicide (American College of Neuropsychopharmacology, 2004). Epidemiological surveys have shown a significant correlation between the reduction in suicides and the increasing prescription of SSRIs, in the United States (Olfson et al. 2003), Sweden (Carsten et al., 2001 and Finland (Ohberg et al., 1998). Suicide in depressed patients, however, is more likely to be associated with failure to take antidepressant medication (Isaacsson et al., 1997). Supportive evidence comes from a post mortem toxicology study of 49 adolescent suicide victims in Utah, of whom $24 \%$ were prescribed antidepressants, but none had traces of SSRIs at the time of death (Gray et al., 2003).

In Britain, where prescribing of antidepressants has more than doubled in the last 15 years, the suicide rate in 12-29 year old age range has not increased since 1990, when SSRIs were first introduced (Gunnell \& Ashby, 2004). The risk/ benefit balance of SSRIs are unclear, because SSRIs are less likely to lead to death in overdose due to their reduced toxicity. It is possible, therefore, that the introduction of SSRIs has lead, in part, to a reduction in the overall suicide rate amongst those at great risk depressed adolescents who take overdoses. (Hawton et al., 2003; Gunnell \& Ashby, 2004) It has been argued that the risk /benefit balance may also be less favourable in those with anxiety and mild depression, in whom suicide is rare (Gunnell \& Ashby, 2004), however, it is in this lower risk group that the recent rise in prescribing has occurred.

Over the whole age span, it is not clear whether SSRIs increase the suicide risk. A meta-analysis by Healy (2003) suggested that there is an excess of suicides and suicide attempts in those using SSRIs compared to placebo, however an analysis of the FDA data set of over 20,000 treatments found no such excess (Khan et al., 2003).

The risk of suicidal behaviour and completed suicide is greatest within the first nine days of starting antidepressant medication (Jick et al., 2004). This is most likely due to the initial lack of antidepressant effect. In the case of SSRIs, however, there is an added factor of an increase in agitation, which precedes the antidepressant effect (Nutt, 2003). Adolescent suicide attributable to SSRI usage, however, appears a rare phenomenon. Data from the UK General Practice Research Database (1993-1999) revealed 15 adolescent suicides (age 10-19 years), but none in those who took antidepressant medication (Jick et al., 2004).

\section{ALTERNATIVE DRUG TREATMENTS}

Tricylics are an alternative drug treatment for depression, however, a systematic review of tricyclic antidepressants (TCA's) in children and adolescents found no benefit (Hazell et al., 1995). A more recent systematic review by the same author (Hazell et al., 2002) found some modest evidence in adolescents but not in children. The effects on quantitative outcomes were, however, small and barely significant $(\mathrm{P}=0.04)$, and there were no differences in categorical measures of outcome. Tricyclic antidepressants are potentially lethal in overdose with three out of seven suicides in 159 cases in a follow-up 
study of adolescent depression (Rao et al., 1993). The informed clinical view is that tricyclic antidepressants demonstrate a small benefit, which does not balance the risk and, therefore, they should not be used

\section{Alternative treatments}

Medication is not the first, or even second, line treatment for mild or even moderate depression. A thorough assessment of the child, family, and school may reveal the need for psychosocial interventions. Secondly, psychological treatments are effective in mild and moderate cases of depression. In a meta-analysis (Harrington et al., 1998) CBT was shown to be effective in $62 \%$ of depressed adolescents versus $36 \%$ of controls - an odds ratio of $3.2(95 \%$ CI 1.9-5.2). The number needed to treat (NNT) was 4; there were, however, three caveats - first, the treatment is not for severe cases; second, the relapse rate is high, suggesting that either top-ups or a more prolonged treatment protocol is required (Compton et al., 2004); and third, over a third do not respond. Interpersonal therapy has also been shown to be effective for the treatment of depression in adolescents (Mufson et al., 2004).

A recent meta-analysis showed a treatment advantage for the combination of antidepressant medication with psychotherapy, especially in trials lasting over 12 weeks (Pampalloma et al., 2004). Further support comes from the Treatment for Adolescents with Depression Study (TAPS) (Treatment for Adolescents With Depression Study Team, 2004). A fluoxetine-CBT combination was significantly superior to: fluoxetine alone ( $\mathrm{p}=.02)$; CBT $(\mathrm{p}=.01)$; and placebo $(\mathrm{P}=.001)$. On the Children's Depression Rating Scale-Revised, the response rates were- fluoxetine- CBT combination $71.0 \%$ (95\% CI 62-80\%); fluoxetine alone 60.6\% (95\%CI 51-70\%); CBT alone 43\%(95\%CI 34-52); placebo $34.8 \%$ (95\%CI 26-44\%).

\section{CONCLUSIONS}

The recent controversy about the use of SSRIs in children and adolescents for the treatment of depression has highlighted a number of concerns - a major one being the failure by the pharmaceutical industry to disclose negative trials. The empirical database is further limited: trials involve mostly cases of mild to moderate depression; exclude individuals with high suicide risk; have short follow-up periods- often less than $8-10$ weeks; have high drop out rates; and are statistically underpowered (exception being the TAPS study).

The evidence that SSRIs increase suicidal behaviour, thoughts or acts is relatively weak. The response from the CSM has been one of caution, and it is doubtful whether there is sufficient validity or justification for extrapolating from the current studies to the treatment of severely depressed adolescents. However, it is in this group, where there is a heightened risk of suicide that one would want an effective treatment. Evidence from adult studies point to the efficacy of SSRIs, and there is no a priori reason why the case should be different for severely depressed adolescents.

\section{Recommendations}

A central requirement for an evidence-based culture in medicine is the disclosure of all trials. From a commercial viewpoint, it is clear that pharmaceutical companies are likely to be reluctant to release negative trials. Nevertheless, some companies have signed up to the good practice guidelines (http://www.gpp-guideli nes.org) and there is an independent resource for registering trials (http://www.controlledtrials.com). Ethical committees need to follow-up all trials and ensure that data including negative data is published or made available. Currently, less than a third of trials are published (Pich et al., 2003). It is clear that further independently funded trials, with samples that match those seen in clinical practice, are needed to research the treatment of childhood depression.

\section{REFERENCES}

American College of Neuropsychopharmacology (2004). Executive Summary. Preliminary Report of Task Force on SSRIs and Suicidal Behaviour in Youth. Retrieved January 11, 2005 from http://www.acnp.org/exec_summary.pdf

BBC News (2003). Panorama: Seroxat: E-mails from the edge. Retrieved January 11, 2005 from http://news.bbc.co.uk/1/hi/programmes/panorama/2982797.stm

Brent D.A. \& Birmaher B. (2004). British wamings on SSRIs questioned. Journal American Academy of Child and Adolescent Psychiatry 43, 379-380.

Carlsten A., Waern M., Ekedahl A. \& Ranstam J. (2001). Antidepressant medication and suicide in Sweden. Pharmacoepidemiology and Drug Safety 10, 525-530.

Committee on Safety of Medicines (2003). Selective Serotonin Reuptake inhibitors (SSRIs) - overview of regulatory status and CSM advice relating to major depressive disorder (MDD) in children and adolescents: summary of clinical trials. London: Committee on Safety of Medicines. Retrieved January 12, 2005 from http://medicines.mhra.gov.uk/ourwork/monitorsafequalmed /safetymessages/SSRIfinal.pdf

Compton S.N., March J.S., Brent D., Albano A.M., Weersing V.R. \& Curry J. (2004). Cognitive-behavioral psychotherapy for anxiety and depressive disorders in children and adolescents: an evidencebased medicine review. Joumal of the American Academy of Child and Adolescent Psychiatry 43, 930-959. 
Emslie G.J., Rush A.J., Weinberg W.A., Kowatch R.A., Hughes C.W. Carmody T. \& Rintelmann J. (1997). A double-blind, randomised placebo-controlled trial of Fluoxetine in children and adolescents with depression. Archives of General Psychiatry 54, 1031-1037.

Emslie G.J., Heiligenstein J.H., Wagner K.D., Hoog, S.L., Ernest D.E. Brown E., Nilsson M. \& Jacobson J.G. (2002). Fluoxetine for acute treatment of depression in children and adolescents: a placebo-controlled, randomized clinical trial. American Academy of Child and Adolescent Psychiatry 41,1205-1215.

Fergusson D.M. \& Woodward L.J. (2002). Mental health, educational, and social role outcomes of adolescents with depression. Archives of General Psychiatry 59, 225-231.

Garland E.J. (2004). Facing the evidence: antidepressant treatment in children and adolescents. Canadian Medical Association 170, 4891345.

Gray D., Moskos M. \& Keller T. (2003). Utah Youth Suicide Study New Findings. Presented at the Annual Meeting of the American Association of Suicidology, Sante Fe, New Mexico.

Gunnell D. \& Ashby D. (2004). Antidepressants and suicide: what is the balance of benefit and harm. British Medical Journal 329(7456), 34 38.

Harrington R., Whittaker J., Shoebridge P. \& Campbell F. (1998). Systematic review of efficacy of cognitive behaviour therapies in childhood and adolescent depressive disorder. British Medical Journal 316,1559-1563.

Hawton K., Rodham K., Evans E. \& Weatherall R. (2002). Deliberate self harm in adolescents: self report survey in schools in England. British Medical Journal 325,1207-1211.

Hawton K., Hall S., Simkin S., Bale L., Bond A., Codd S. \& Stewart A. (2003). Deliberate self-harm in adolescents: a study of characteristics and trends in Oxford, 1900-2000. Journal of Child Psychology and Psychiatry 44, 1191-1198.

Hazell P., O'Connell D., Heathcote D., Robertson J. \& Henry D. (1995). Efficacy of tricyclics drugs in treating child and adolescent depression: a meta-analysis. British Medical Journal 310, 897-901.

Hazell P., O'Connell D., Heathcote D. \& Henry D. (2002). Tricyclic drugs for depression in children and adolescents. Cochrane Database of Systematic Reviews, Issue 2.

Healy D. 2003). Lines of evidence on the risks of suicide with selective serotonin reuptake inhibitors. Psychotherapy and Psychosomatics 72, 71-79.

Isacsson G. (2000). Suicide prevention-a medical breakthrough? Acta Psychiatrica Scandanavica 102, 113-117.

Isacsson G., Holmgren P., Druid H. \& Bergman U. (1997). The utilisation of antidepressants - a key issue in the prevention of suicide: an anlysis of 5281 suicides in Sweden during the period 1992-1994. Acta Psychiatrica Scandanavica 96, 94-100.

Jick H., Kaye J.A. \& Jick S.S. (2004). Antidepressants and the risk of suicidal behaviours. Journal of the American Medical Association $292,338-343$.

Jureidini J.N., Doecke C.J., Mansfield P.R., Haby M.M., Menkes D.B. \& Tonkin A.L. (2004). Efficacy and safety of antidepressants for children and adolescents. British Medical Journal 328, 879-883.

Keller M.B., Ryan N.D., Strober M., Klein R.G., Kutcher S.P., Birmaher B., Hagino O.R., Koplewicz H., Carlson G.A., Clarke G.N., Emslie G.J., Feinberg D., Geller B., Kusumakar V., Papatheodorou G., Sack W.H., Sweeney M., Wagner K.D., Weller E.B., Winters N.C., Oakes R. \& McCafferty J.P. (2001). Efficacy of paroxetine in the treatment of adolescent major depression: a randomized, controlled trial. Joumal of the American Academy of Child and Adolescent Psychiatry 40, 762-772.

Khan A., Khan S., Kolts R. \& Brown W.A. (2003). Suicide rates in clinical trial of SSRIs, other antidepressants, and placebo: analysis of FDA reports. American Joumal of Psychiatry 160, 90-792.

Mandoki M.W., Tapia M.R., Tapia M.A., Sumner G.S. \& Parker J.L. (1997). Venlafaxine in the treatment of children and adolescents with major depression. Psychopharnacology Bulletin 33, 149-154.
McClure M. (2001). Suicide in children and adolescents in England and Wales 1970-1998. British Medical Journal 178, 469-474.

Mufson L., Dorta P., Wickramaratne P., Nomura Y., Olfson M. \& Weissman M.M. (2004). A randomized effectiveness trial of interpersonal psychotherapy for depressed adolescents. Archives of General Psychiatry 61, 577-584.

Nutt D.J. (2003). Death and dependence: current controversies over the selective serotonin reuptake inhibitors. Journal of Psychopharmacology 17, 355-364.

Ohberg A., Vuori E., Klaukka T. \& Lonnqvist J. (1998). Antidepressants and suicide mortality Journal of Affective Disorders 50, 225-233.

Olfson M., Shaffer D., Marcus S.C. \& Greenberg T. (2003). Relationship between antidepressant medication treatment and suicide in adolescents. Archives of General Psychiatry 60, 978-982.

Pich J., Carne X., Arnaiz J.A., Gomez B., Trilla A. \& Rodes J. (2003). Role of a research ethics committee in follow-up and publication of results. Lancet 361, 1015-1016.

Poznanski E.O. \& Mokros H.B. (1996). Manual: Children's Depression Rating Scale-Revised. Western Psychological Services: Los Angeles.

Poznanski E.O., Cook S.C. \& Carroll B.J. (1979). A depression rating scale for children. Pediatrics 64, 442-450.

Ramchandani P. (2004"). Treatment of major depressive disorder in children and adolescents: most selective serotonin reuptake inhibitors are no longer recommended. British Medical Journal 328, 518-520.

Ramchandani P. (2004b). A question of balance: how safe are the medicines that are prescribed to children? Nature 430, 401-402.

Rao U., Weissman M.M., Martin J.A. \& Hammond R.W. (1993). Childhood depression and risk of suicide: preliminary report of a longitudinal study. Jourmal of the American Academy of Child and Adolescent Psychiatry 32, $21-27$.

Simeon J.G., Dinicola V.F., Fergusson H.B. \& Copping W. (1990). Adolescent depression: a placebo-controlled fluoxetine treatment study and follow-up. Progress in Neuro-Psychopharmacology \& Biological Psychiatry 14, 791-795.

Treatment for Adolescents With Depression Study Team (2004). Fluoxetine, cognitive-behavioral therapy, and their contribution for adolescent with depression: Treatment for Adolescents With Depression Study (TADS) randomized controlled trial. Journal of American Medical Association 292, 807-820.

US Food and Drugs Administration (2004). FDA Statement on Recommendations of the Psychopharmacologic Drugs and Pediatric Advisory Committee. Retrieved January 11, 2005 from http://www.fda.gov/bbs/topics/news/2004/NEW01116.html

Wagner K. D., Ambrosini P., Rynn M., Wohlberg C., Yang R., Greenbaum M.S., Childress A., Donnelly C. \& Deas D. (2003). Sertraline Pediatric Depression Study GroupEfficacy of sertraline in the treatment of children and adolescents with major depressive disorder. Journal of the American Medical Association 290, 1033. 1041.

Wagner K.D., Robb A.S., Findling R.L., Jin J., Gutierrez M.M. \& Heydorn W.E. (2004). A randomised, placebo-controlled Trial of citalopram for the treatment of major depression in children and adolescents. American Journal Psychiatry 161, 1079-1083.

Wessely S. \& Kerwin R. (2004). Suicide risk and the SSRIs. Journal of the American Medical Association 292, 379-381.

World Health Organisation (2003). Suicide Prevention and special programmes. Country reports and charts available. Retrieved January 11, 2005 from http://www.who.int/mental_health/prevention/suicide/country_reports/en/

Whittington C.J., Kendall T., Fonagy P., Cottrell D., Cotgrove A. \& Boddington E. (2004). Selective serotonin reuptake inhibitors in childhood depression: systematic review of published versus unpublished data. Lancet 363, 341-1345. 